\title{
Buriat dorsal epenthesis is not reproduced with novel morphemes
}

\author{
Peter Staroverov \\ Department of English, Program in Linguistics, Wayne State University, USA \\ E-mail: peter.staroverov@gmail.com
}

\begin{abstract}
In Buriat, the consonant realised contextually as dorsal or uvular alternates with zero at stemsuffix boundaries. This alternation has been analysed as phonological epenthesis and has been known as a challenge to the existing theories of phonological markedness. The analysis of this alternation has also been debated. This paper presents new fieldwork and experimental "wug"testing evidence addressing the productivity of the reported epenthesis pattern. The results do not fully support the phonological insertion account of the alternation. An alternative analysis of Buriat dorsal-zero alternation in terms of floating features is proposed.
\end{abstract}

Keywords: Buriat, Mongolic, epenthesis, insertion, dorsal, phonological markedness

\section{Introduction}

The analysis of alternations between a consonant and zero is associated with a long-standing problem - the deletion-insertion ambiguity (Hale 1973, McCarthy 1991, Baković 1999, Morley 2015). Both kinds of analyses have been proposed for many known cases such as English dialectal r-zero alternations (McCarthy 1991, 1993; Harris 1994; Baković 1999; Gick 1999 amongst others), French liaison (Klausenburger 1974, 1977; Churma 1977; Tranel 1981, 1996; Wetzels 2002 amongst others), and Maori passive (Hale 1973, de Lacy 2003 amongst others). The typology of consonant-zero alternations is accordingly debated (Lombardi 2002; de Lacy 2002, 2006; Blevins 2008; Rice 2008; Hall 2013; Staroverov 2014), and Morely (2015) argues that it may not be possible to come up with general criteria that would differentiate between deletion and insertion cross-linguistically.

Buriat presents a famous and controversial case of consonant-zero alternations where the consonant realised contextually as dorsal $[\mathrm{g}, \mathrm{\gamma}]$ or uvular $[\mathrm{G}, \mathrm{b}]$ alternates with zero at stemsuffix boundaries between any two bimoraic vowels (Poppe 1938, 1960; Sanžeev 1941; Sanžeev, Bertagaev and Tsidendambaev 1962; Čeremisov 1973; Skribnik 2003). Although this alternation has been analysed as phonological epenthesis (Rice 2008, Morley 2015, Vaux and Samuels 2017, Samuels and Vaux 2019), several arguments against a productive epenthesis process have been presented. Many existing theories of markedness assume that coronal epenthesis is universally preferred to dorsal epenthesis, and since Buriat has coronal consonants, these theories imply that the Buriat alternation is suppletive or lexicalised (de 
Lacy 2006, de Lacy and Kingston 2013). Relatedly, a pattern of dorsal insertion would constitute a perceptually non-minimal change or saltation, and we would therefore expect a learning bias against this pattern, based on the results of White (2014). Indeed, the VV sequences are phonetically most similar to V-glide-V (Delattre, Liberman and Cooper 1955; Liberman et al. 1956; O'Connor et al. 1957; Wright 2004), but the inserted consonant is not a glide. Finally, some results from artificial grammar learning experiments also speak for a bias against productive epenthesis rules (Morley 2018).

Many well-known phonological alternations have been argued to be unproductive (Alderete and Kochetov 2009; Zhang and Lai 2008; Zhang, Lai and Sailor 2011; Zhang 2016 amongst others), and for Buriat this is suggested by Staroverov (2016). Thus the inherent ambiguity of consonantzero alternations as well as the theoretical expectations and preliminary results outlined above all call for a detailed investigation of the psychological reality of Buriat dorsal insertion.

This paper presents new elicitation and experimental evidence in order to test whether the reported epenthesis pattern is productive. The results of an experiment using "wug"-test methodology do not fully align with the hypothesis of a general insertion process, since only one speaker out of nine consistently generalised the reported dorsal/uvular insertion pattern. However, a more extensive experimental study may be needed to fully establish these results. New elicitation data on numerals also do not show consistent generalisation of /g/-insertion.

Motivated by these new results, I propose an alternative account of the Buriat facts where the dorsal/uvular consonant alternating with zero corresponds to an underlying floating feature (e.g. Zoll 1996) similar to a featural affix (Akinlabi 1996, 2011). The paper explores the implications of this new account, and the ways of testing its predictions.

After introducing some background on Buriat (section 2), the potential accounts of the dorsalzero alternation are introduced in section 3. Section 4 considers new elicitation evidence that bears on the possibility of dorsal epenthesis, and section 5 presents the experiment. The proposed alternative analysis is laid out in section 6 , and section 7 concludes the paper.

\section{Buriat basics}

This section briefly surveys the aspects of Buriat phonology relevant to dorsal-zero alternations. All the data in this article come from my field investigation of the Barguzin dialect of Buriat (Radnaev 1965) as spoken in the village of Baragkhan (see also Bondarenko (2017a, 2017b, $2018 \mathrm{a}, 2018 \mathrm{~b}$ ) for some recent results on the syntax of this dialect). Unless otherwise noted, the generalisations do not differ substantially from Standard Buriat. More details on the consultants can be found in section 5.1.3. The transcription used here adheres to IPA.

The vowel inventory of Barguzin Buriat is given in (1). ${ }^{1}$ Except for /ei/, all of these vowels contrast in the first syllable, while /ei/ only occurs in non-first syllables. The vowel inventory includes underlying short vowels, long vowels, and diphthongs. On the surface, some

\footnotetext{
${ }^{1}$ Vowel quality is reported based on my preliminary formant measurements. Compared to Standard Buriat (Buraev 1959; Radnaeva 2003a, 2003b, 2006, 2008), the high rounded vowels appear to be [ $\mathrm{u} u$ : ] rather than [U $v:]$. The mid front vowels are centralised [э э:] rather than [e e:]. The non-high vowels transcribed as [o a] here can have a quality closer to the Standard Buriat [ $\left[\begin{array}{l}\mathrm{a}\end{array}\right]$, but my data are not sufficient to firmly establish the general pronunciation of these vowels in Barguzin Buriat.
} 
underlying diphthongs appear as long monophthongs but their underlying status is revealed in vowel harmony, which is controlled by the first member of the underlying diphthong. In a number of morphemes, /oi/ is realised close to [e:] in the Barguzin dialect; these morphemes pattern with other instances of /oi/ [œe] with respect to harmony.

(1) Buriat vowel inventory

\begin{tabular}{|c|c|c|c|}
\hline \multicolumn{3}{|c|}{ Underlying monophthongs } & Underlying diphthongs \\
\hline i i: & $\mathrm{H}$ u: & u u: & /ai/ $\varepsilon:$ /oi/ œe /ui/ ui \\
\hline ๑ ૭: & $\begin{array}{c}\theta: \\
a^{2}\end{array}$ & o o: & \\
\hline
\end{tabular}

Non-first syllables present a reduced vocalic inventory lacking the short $[\mathrm{u} u]$. The vowels in non-first syllables are also subject to phonetic reduction, which is not marked in my transcription: long vowels are shorter and short /o a/ are realised with a schwa-like quality (see Svantesson et al. (2005) for a similar reduction process in Mongolian).

Buriat has vowel harmony in frontness and rounding. Rounding harmony is not immediately relevant to our purposes, and while it is described somewhat differently in my main sources (Poppe 1960; Sanžeev, Bertagaev and Tsidendambaev 1962; Skribnik 2003), the studied dialect seems to match the description of Skribnik (2003). The principles of frontness harmony also mostly match what is reported for Standard Buriat. In what follows, I use frontness harmony as a standard for productive processes, and compare its productivity to that of dorsal-zero alternations (see also Poppe 1960: 21). All vowels within a word agree in frontness, hence every word may contain either the vowels from a relatively back set /a a: ai o o: oi u u: ui/ or the vowels from a relatively front set /९ ९: ei $\Theta: \mathrm{u} u: \mathrm{ui} /$. The frontness value of the word is controlled by the first syllable vowel. The vowels / $\mathrm{i}$ :/ act as neutral, occurring in both kinds of words. /i:/ triggers front harmony if it occurs in the first syllable. The phonetic basis of frontness harmony is obscured by the realisation of diphthongs, e.g. /ai/ patterns as a back vowel even though it is realised as a front vowel $[\varepsilon:]$.

The set of vowels in non-first syllables is limited to only seven underlying options, which will be symbolised as follows: /A/, /Ai/, /A:/, /U:/,/Ui/, /i/, /i:/. The so-called particles, such as the negation /gui/ [gyi], are known to escape harmony and start their own harmony domain (Poppe 1960). The studied dialect also has a number of non-harmonising suffixes which are absent in Standard Buriat. The particles and non-harmonising dialectal suffixes will be written here with an underlying lower case vowel symbol.

The Buriat consonant inventory appears in (2). The segments in parentheses occur only in loanwords.

(2) Buriat consonants

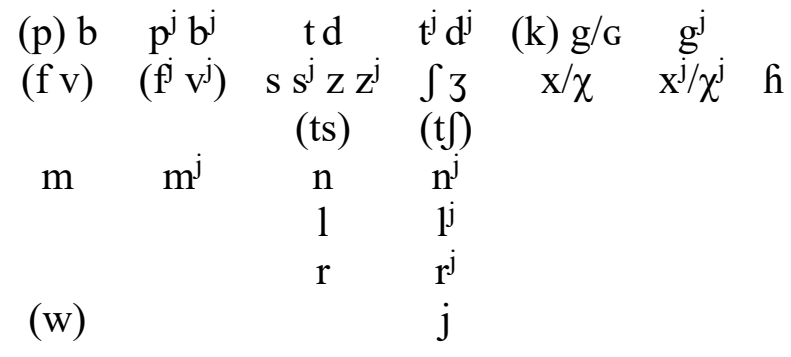


The phonetic realisation of voiced dorsal/g/ (both underlying and "epenthetic") varies with the vowel harmony class of the word. In front-vowel words, this segment appears as [g] and sometimes undergoes lenition to [y] intervocalically. In back-vowel words, it appears as uvular [G] and frequently lenites to [в] between vowels. In what follows, this segment will be loosely referred to as "dorsal". The dorsal fricative / $\mathrm{x}$ / varies according to similar principles, although the details of its positional allophones are not extensively studied here.

Buriat allows syllables to begin with a vowel only word-initially. Native Buriat words disallow onset clusters and only allow $[\mathrm{ng}]$ as a complex coda. The syllable structure for native words is thus CVCC word-medially and (C)VCC word-initially. Loanwords (mainly from Russian) allow larger consonant clusters in both onset and coda. A description of stress in the studied dialect is left for future research. See Poppe (1960) and Walker (1994) for a description of stress in Standard Buriat.

\section{Buriat dorsal-zero alternation}

The following section (3.1) describes the patterns of hiatus resolution in Buriat. In order to assess the predictions for novel items, the possible alternative analyses of the $/ \mathrm{g} /$-zero alternations are presented in sections 3.2-3.5.

\subsection{Hiatus resolution: The data}

Barguzin Buriat allows no word-medial vowel-initial syllables, and this generalisation is also known from the descriptions of Standard Buriat (Sanžeev 1941, Poppe 1960). Diphthongs that is, sequences of vowels within a syllable - are allowed, e.g. [œe, ui, yi]. Buriat has no prefixes, so only suffixal boundaries are relevant to hiatus resolution. Although the underlying representations for some of the examples are debated, unambiguous surface morpheme boundaries are shown for ease of reference. The symbol $(\mathrm{g})$ will be used to refer to the dorsal alternating with zero, where its underlying status is left unspecified.

To set the scene, the behaviour of consonant-final stems is illustrated in (3). ${ }^{2}$ These stems end in a consonant in isolation or before consonant-initial suffixes such as /xA/ 'infinitive' (3a). In (3b), these stems are followed by vowel-initial suffixes. Most vowel-initial suffixes uncovered so far begin with a long vowel or diphthong. Although Barguzin Buriat has a couple of vowel-initial suffixes starting with a short vowel, these suffixes do not trigger/g/-insertion and are thus irrelevant.

(3) Buriat consonant-final stems and vowel-initial affixes

a. [xatar-xa] 'dance-INF'

[burgod] 'eagle'

[hu:l] 'tail'

b. [xatar-a:] 'dance-IPF'

[burgod-e:r] 'eagle-INSTR'

[hu:l-э:r] 'tail-INSTR'

[burgэd-a:n] 'eagle-ABL.DIAL'

\footnotetext{
${ }^{2}$ The following abbreviations are used in the glosses: ABL.DIAL - dialectal ablative, CAUS(ative), COMIT(ative), DAT(ive), FREQ(uentative), INF(initive), INSTR(umental), IPF - imperfective, PASS(ive), PL.IMP - plural imperative, PST - past.
} 
The examples in (4) illustrate the stems that I will refer to as "short vowel stems". These end in a short vowel in isolation (4a). When short vowel stems are followed by vowel-initial suffixes, hiatus is resolved by vowel deletion, as shown in (4b).

(4) Buriat short vowel stems and vowel deletion

a. [nabja] 'leaves'

[Jono] 'wolf'

b. [nabf-a:r] 'leaves-INSTR'

[Jon-a:n] 'wolf-ABL.DIAL'

The /g/-zero alternations happen after long vowel stems (5). These stems end in a long vowel or a diphthong in isolation or before a consonant-initial suffix (5a). When long vowel stems are followed by (long) vowel-initial suffixes, a dorsal/uvular sound appears between the two vowels. The surface $[\mathrm{g}, \mathrm{\gamma}, \mathrm{G}, \mathrm{s}]$ allophones are distributed according to the general pattern of $/ g /$-realisation (see section 2). The dorsal also appears between the comitative suffix [t $\varepsilon$ : ], which is shown word-finally in (5c), and the instrumental, which is illustrated in (3). The comitative + instrumental combination is shown in $(5 \mathrm{~d}) .^{3}$

(5) Buriat long vowel stems and the /g/-zero alternation
a. [xul'j:-dэg] 'wait-FREQ'
[bu:] 'gun, rifle'
[tax ${ }^{\mathrm{j} a} \mathrm{a}$ '] 'hen'
b. [bu:ка:r] 'rifle-INSTR'
[xulj9:g9:] 'wait-IPF'
[tax ${ }^{j}$ a: $\left.\mathbf{z a}: n\right]$ 'hen-ABL.DIAL'
c. [hurga:1-t $\varepsilon$ :] 'education-COMIT'

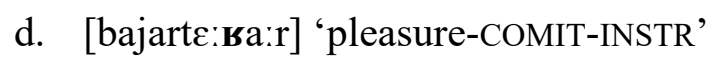

To summarise, while a potential sequence of a short + long vowel triggers vowel deletion in Buriat (4), the potential sequences of bimoraic vowels show up with a surface dorsal $(5 b, d)$. This dorsal segment is absent from the relevant stems and suffixes in other contexts ((3) and $(5 \mathrm{a}, \mathrm{c}))$. The stem classes in $(3-5)$ are quite pervasive in Buriat; they all include a large number of stems. The following suffixes trigger the /g/-zero alternation in the studied dialect: $/(\mathrm{g}) \mathrm{A}: \mathrm{r} /$ 'instrumental'; /(g)a:n/ 'ablative (dialectal)';/(g)A:d/ 'approximative'; /(g)A:/ 'imperfective, imperfective participle'; /(g)a:n/ 'perfective, perfective participle (dialectal)'; /(g)A:SA/ 'habitual participle'; /(g)A:d/ 'perfective gerund'; /(g)A:rAi/ 'future imperative'; /(g)i:/ 'nonfuture second-person imperative'; /(g)U:3An/ 'non-future third-person imperative'. ${ }^{4}$ Finally, the suffix-suffix combinations are rather restricted but the comitative + instrumental sequences illustrated in $(5 \mathrm{c}-\mathrm{d})$ also show /g/-zero alternations.

\footnotetext{
${ }^{3}$ The combination of comitative and instrumental affixes also has a fast speech dialectal variant $/ \mathrm{t}^{\mathrm{j}} \mathrm{AAr} / \mathrm{showing}$ apparent vowel deletion, e.g. /noxoi-tAi-A:r/ [noxœet'o:r] 'dog-COMIT-INSTR'.

4 This list is similar to that compiled by Morley (2015) for Standard Buriat, but it includes a few dialectal morphemes and excludes the morphemes which are not used in the studied dialect. In addition to these, Poppe (1960) also lists a number of derivational suffixes which start with a long vowel but which are not recorded after stems ending in long vowels (see also Morley 2015: fn. 10). These derivational affixes are of limited productivity: they do not attach to the relevant stems and some are absent in the studied dialect altogether.
} 


\subsection{Deletion account and the non-alternators}

In order to narrow down the space of possible hypotheses about Buriat data, this section presents evidence against a deletion analysis (Uffmann 2014). The deletion account has two varieties exemplified in (6) with stems and suffixes from (3-5). On the one hand, long vowel stems could underlyingly end in /g/, coupled with word-final and pre-consonantal /g/-deletion (6a). On the other hand, vowel-initial suffixes could start underlyingly in $/ \mathrm{g} /$ and, in this case, $/ \mathrm{g} / \mathrm{would}$ be deleted after consonants (6b).

(6) Deletion analyses of the Buriat data
Stem URs: examples
Suffix URs: examples
Deletion examples
a. /xul's:g/ 'wait'
/A:/ 'IPF'; /dAg/ 'FREQ'
$/ \mathrm{xul} \mathrm{j}_{\mathrm{j}}: \mathrm{g}-\mathrm{dAg} / \rightarrow$
/xatar/ 'dance'
$\left[\mathrm{xul}^{\mathrm{j}} \mathrm{g}: \mathrm{d}\right.$ gg] 'wait-FREQ'
b. /xul's:/ 'wait'
/gA:/ 'IPF'; /dAg/ 'FREQ'
/xatar-gA:/ $\rightarrow$
/xatar/ 'dance'
[xatara: 'dance-IPF'

Although an analysis along these lines has been considered by Uffmann (2014) and Morley (2015), some additional predictions have not been fully explored. If Buriat phonology included one of the deletion processes in (6), then we would expect that $\mathrm{g}+\mathrm{C}$ or $\mathrm{C}+\mathrm{g}$ clusters would be absent or at least restricted in Buriat. The examples of non-deletion of $/ \mathrm{g} /$ next to a consonant are thus potential counterexamples to the deletion accounts. Hall (2013) argues for a similar criterion applied to rhotic-zero alternations.

However, both my elicitations and the existing descriptions of Standard Buriat present multiple examples of $\mathrm{C}+\mathrm{g}$ and $\mathrm{g}+\mathrm{C}$ sequences across a variety of morphological environments. Some examples are given in (7a) for $\mathrm{gC}$ sequences and in (7b) for $\mathrm{Cg}$ sequences.

(7) Preservation of $/ \mathrm{g} /$ next to a consonant
a. [bosog-to] 'letter-DAT'
[zuras-ta] 'drawing-DAT'
[tan $\mathrm{j}_{\mathrm{i}}$-gda-ba] 'recognize-PASS-PST'
[jaba-gti:] 'walk-PL.IMP'
b. [E:-lga:] 'fear-CAUS.IPF'
[malge:] '(winter) cap'
[xargi:] 'road'
[ba:bge: 'bear'

Thus Buriat has a good deal of stems which end in a non-alternating /g/, illustrated by the first two examples in (7a). Buriat also has a number of suffixes beginning in a non-alternating $/ \mathrm{g} /$, illustrated by the suffixes /-gdA/ 'passive' and /-gti:/ 'plural imperative' in (7a). (7b) shows $\mathrm{C}+\mathrm{g}$ sequences stem-internally and suffix-initially. The suffixes which would begin in $/ \mathrm{g} /$ followed by a vowel seem hard to come by, but given that both $\mathrm{g}+\mathrm{C}$ and $\mathrm{C}+\mathrm{g}$ sequences are abundant, it is not clear how this gap could be incorporated in a possible deletion analysis.

To summarise, the potential accounts where $/ \mathrm{g} /$ is deleted before or after a consonant face multiple counterexamples from $\mathrm{g}+\mathrm{C}$ and $\mathrm{C}+\mathrm{g}$ clusters. The abundance of counterexamples to $/ \mathrm{g} /$-deletion can be taken as evidence against the deletion accounts, while other accounts do not 
face this problem. The only potential argument for deletion accounts could come from the absence of suffixes starting in a $\mathrm{g}+\mathrm{V}$ sequence. However, since suffixes are a closed class, this gap could be accidental. I will not be considering the deletion analysis in what follows, but I do acknowledge that further work may be needed to show that the lack of $g+V$-initial suffixes is a non-productive generalisation.

This section has argued that the presence and generality of a consonant deletion process can be falsified by considering potential counterexamples, i.e. instances where $/ \mathrm{g} /$ does not alternate with zero in appropriate environments. Hall (2013) applies a very similar criterion in a typological study of rhotic-zero alternations. These results go against the idea that deletion is not distinguishable from insertion cross-linguistically (Morley 2015).

\subsection{Insertion account}

The insertion account of the /g/-zero alternation is schematised in (8) based on the examples in (3-5) (see also Rice 2008, Morley 2015, Samuels and Vaux 2019).

(8) Insertion analysis of the Buriat data

\begin{tabular}{|c|c|c|}
\hline $\begin{array}{l}\text { tem URs: examples } \\
\text { xul' }^{\mathrm{j}} \text { :/ 'wait' } \\
\text { xatar/'dance' }\end{array}$ & $\begin{array}{l}\text { Suffix URs: examples } \\
\text { /A:/ 'IPF' }\end{array}$ & 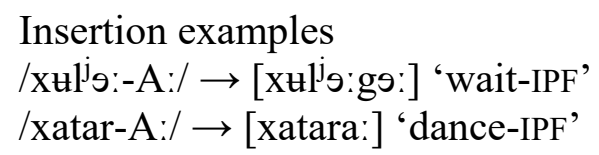 \\
\hline
\end{tabular}

On this analysis, the long vowel stems underlyingly end in a vowel, and vowel-initial suffixes have no initial underlying consonant. A voiced dorsal consonant is inserted between any two bimoraic nuclei. The potential counterexamples to this analysis would be cases of unresolved hiatus, but these do not occur either in the elicitation results or in the existing descriptions. The insertion process described above also seems to be fairly general morphologically, i.e. it applies with a large number of suffixes and in all recorded cases of relevant suffix-suffix boundaries. De Lacy and colleagues cite two affixes which involve suppletive alternations instead of /g/-insertion in a similar context (de Lacy 2006, de Lacy and Kingston 2013) - these will be discussed in more detail in section 3.4 below. However, the number of suppletive suffixes is small compared to the number of suffixes which trigger the /g/-zero alternation (see also Morley 2015).

As outlined in section 1, there are a few theoretical arguments against a general process of dorsal insertion. Although an insertion account seems to capture the Buriat data relatively well, both the place markedness theory of epenthesis (de Lacy 2006) and the existing evidence for an anti-saltation bias in learning (White 2014) lead us to expect that dorsal insertion may be non-productive or underlearned (Hayes et al. 2009; Zhang, Lai and Sailor 2011), even in the presence of relatively robust evidence.

\subsection{Morphological accounts}

This section describes possible approaches to the Buriat /g/-zero alternations where the alternation is not handled by the productive phonology of the language. This idea can be implemented in a number of ways. For example, the data in (5) could stem from a pattern of phonologically-conditioned suppletion (de Lacy 2006, de Lacy and Kingston 2013). On the suppletion account, the vowel-initial affixes have a lexically stored /g/-initial variant, thus the instrumental affix would have allomorphs /gA:r/ and /A:r/. An important assumption behind 
the suppletion analysis is that g-zero alternation is limited to only a few suffixes, and it is a mere accident that these affixes have a very similar pattern of suppletive allomorphy (de Lacy and Kingston 2013: 304). Although Buriat does have some affixes that exhibit irregular hiatus resolution strategies such as the reflexive accusative, the number of affixes triggering the dorsal-zero alternation is quite large (see section 3.1 and Morley (2015)), and therefore it seems unlikely that all of these affixes accidentally have the same suppletive allomorphs.

Another possible morphological account would assume that all relevant affixes start with a floating feature DORSAL (Akinlabi 1996, Zoll 1996), or possibly a bundle of features, which I will write as $/ \mathrm{g} /$. This account is summarised in (9). The floating $/ \mathrm{g} /$ is realised only between two bimoraic nuclei, and is otherwise left unrealised.

(9) Floating /g/ analysis of the Buriat data

\begin{tabular}{|c|c|c|}
\hline $\begin{array}{l}\text { Stem URs: examples } \\
\text { /xul' }{ }^{\prime} \text { g: ' wait' } \\
\text { /xatar/ 'dance' }\end{array}$ & $\begin{array}{l}\text { Suffix URs: examples } \\
/{ }^{\mathrm{g}} \mathrm{A}: / \text { 'IPF' }\end{array}$ & 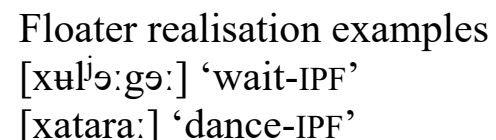 \\
\hline
\end{tabular}

On this account, Buriat phonology handles the realisation and non-realisation of the floating features, but the quality of a consonant alternating with zero is specified underlyingly for each affix. The floating /g/ account seems to capture the syllabic motivation for the realisation of a dorsal. However, on this story it is a coincidence that so many suffixes have $/ \mathrm{g} /$ rather than some other consonant alternating with zero.

Finally, one could assume that the floating /g/ is part of the stem, but this possibility is not entertained here for two reasons. First, the stems are an open class, and it seems that it would be a highly unlikely coincidence that all stems that have a final syllable with a bimoraic vowel and no coda also have a floating $/ \mathrm{g} /$. Second, many of the relevant stems show a morphologically governed $/ \mathrm{n} /$-zero alternation in other environments (see section 4 ), and it is not clear how the floating $/ \mathrm{g} /$ on the stem would combine with floating $/ \mathrm{n} /$.

To summarise, this section has presented the possible morphological accounts incorporating the assumption that the dorsal-zero alternation is encoded in the lexicon, at least partially. While these accounts capture the data, they seem to face an issue in explaining the fact that dorsals alternate with zero according to the same set of rules with a large number of suffixes.

\subsection{Summary and predictions}

This section has considered the possible treatments of the dorsal-zero alternation in Buriat. The deletion analysis faces multiple counterexamples from unresolved $\mathrm{C}+\mathrm{g}$ and $\mathrm{g}+\mathrm{C}$ clusters, and therefore it will not be considered further here (pace Morley 2015). According to the insertion account, Buriat has a general phonological alternation inserting a dorsal between two bimoraic nuclei (Morley 2015, Vaux and Samuels 2017). On the other hand, according to the morphological accounts, the dorsal alternating with zero is part of the underlying specification of the relevant suffixes (de Lacy 2002, 2006; de Lacy and Kingston 2013; Uffmann 2014). The morphological accounts have to assume that a large number of suffixes accidentally match in their morphophonological behaviour. 
Importantly, the two accounts make different predictions for the productivity of dorsal-zero alternations. These predictions specifically apply to new affixes, since morphological accounts postulate that the alternating dorsal is part of an affix. ${ }^{5}$ The phonological insertion account predicts that new and unfamiliar suffixes that start in a long vowel will trigger the application of dorsal insertion. On the other hand, the morphological account assumes that the long-vowel-initial suffixes listed in section 3.1 underlyingly start with a floating $/ \mathrm{g} /$. Its predictions will then be distinct from those of the phonological insertion story provided that two assumptions are true: first, I assume that the existence of native affixes starting with a floating /g/ does not by itself force the learner to postulate a floating /g/ when novel suffixes are encountered. If such an automatic generalisation existed, it would make the morphological account empirically indistinguishable from the phonological insertion story. Second, I propose that the postulation of a latent segment or of floating features on a novel affix only occurs if the learner receives positive evidence of an alternation. For most native affixes in section 3.1, such evidence is encountered in Buriat inflectional morphology. However, when there is no positive evidence of dorsal-zero alternation, the speakers may generalise the native hiatus resolution strategies (vowel deletion, /g/-insertion) or attempt to guess the floating features on the suffix.

To summarise, if the phonological insertion analysis is empirically different from the morphological accounts at all, they will differ on novel and unfamiliar affixes. Therefore, the difference between the two accounts can be addressed with productivity experiments (Berko 1958) as well as with recovery experiments (Chuang, Chang and Hsieh 2011).

The rest of this paper presents new evidence of how Buriat speakers treat new or unfamiliar suffixes. Section 4 presents new elicitation results on the suffix /-A:dA:r/ which attaches to numerals and carries an adverbial distributive meaning (e.g. 'in pairs', 'in bundles of three', etc.). Section 5 reports on the results of an experiment with a made-up augmentative suffix /-A:bA/.

\section{The numeral distributive}

Experiments with made-up "wug" non-words have served as a way of assessing speakers' knowledge of rules since Berko's (1958) publication. However, using the "wug" items does not always guarantee that the speakers will treat these as native words, and it does not exclude the possibility that the non-application of native phonological rules is due to failed nativisation (Chuang, Chang and Hsieh 2011). As a way to address this concern, this section reports on a native suffix that commonly occurs with only a few stems - the numeral distributive /-A:dA:r/. Combining this suffix with stems with which it was probably never seen before shows whether /g/-insertion may be internalised as a general phonological process by the speakers.

The numeral distributive roughly translates to 'in bunches of size $X$ ' where $X$ is determined by the numeral stem. The suffix is expected to occur commonly with the numeral /xojor/ 'two' (in contexts of people working, walking etc. in pairs), and perhaps with the stem /zu: $\mathrm{n} /$ 'hundred' (in contexts of exchanging a larger bill with bills of a hundred). It is likely that the consultants had never produced, and perhaps had never heard, this affix with a variety of other numerals. This affix thus serves as a potential novel environment for $/ \mathrm{g} /$-zero alternations. On the phonological insertion account, the amount of exposure to this particular suffix with particular stems should not matter, since Buriat dorsal insertion is a general phonological

\footnotetext{
${ }^{5}$ However, it is useful to think about the implications of the morphological accounts for novel stem + native affix combinations. I leave this issue for future research, and I thank an anonymous reviewer for pointing this out.
} 
alternation affecting all sequences of bimoraic vowels. On the morphological account, however, encountering the suffix with only a few stems may not constitute enough positive evidence to postulate a latent segment as part of the suffix, and therefore other hiatus resolution strategies may arise in the novel contexts.

The examples in (10) illustrate the underlying shape of the numeral distributive and of some numeral stems. The distributive surfaces with a long vowel after numeral stems ending in a short vowel or in a consonant (10a). On the other hand, the numeral stems which end in a bimoraic vowel do trigger dorsal-zero alternations in the instrumental (10b).

(10) Numeral distributive and numeral stems contain a long vowel

a. Numeral distributive with consonant-final stems

/xojor-A:dA:r/ [xojoro:do:r] 'in bundles of two'

$/$ taba $^{\mathrm{n}}-\mathrm{A}: \mathrm{dA}: \mathrm{r} / \quad$ [taba:da:r] 'in bundles of five'

b. Numeral stems with other suffixes

$\begin{array}{ll}\text { /zurga:-A:r/ } & \text { [zurьa:вa:r] 'six-INSTR' } \\ \text { /dolo:" }- \text { A:r/ } & \text { [dolo:вo:r] 'seven-INSTR' } \\ \text { /zu:"-A:r/ } & \text { [zu:вa:r] 'hundred-INSTR' }\end{array}$

Some of the stems in (10b) end in a $/ \mathrm{V}: \mathrm{n} /$ sequence containing a floating $/ \mathrm{n} /$. The distribution and realisation of floating $/ \mathrm{n} /$ is entirely morphological: some stems have $/ \mathrm{n} /$ while others do not, and $/ \mathrm{n} /$ is obligatorily realised in some morphological contexts (e.g. the nominative) and never in others (e.g. the instrumental). We can assume that morphology determines if $/ \mathrm{n} /$ is realised or not, hence for phonological purposes stems in $/ \mathrm{n} /$ either have a final consonant (in some forms) or end in a vowel (in others). As a result, when the floating $/ \mathrm{n} /$ is not realised, the $/ \mathrm{V}: \mathrm{n} /$ stems pattern exactly as long vowel stems, and hence a dorsal appears after these stems and before bimoraic vowel-initial suffixes (10b). Whenever possible, I use the stems clearly ending in a bimoraic vowel without $/ \mathrm{n} /$ to illustrate dorsal-zero alternations. However, since numeral stems are a small class and many numerals end in $/ \mathrm{V}: \mathrm{n} /$, such stems are also cited here as relevant.

The insertion account makes a prediction about the combination of the numeral distributive with the stems in (10b): dorsal epenthesis is expected to occur in this case. This prediction is not fully confirmed, as illustrated by the data in (11). All forms here come from two consultants. The same forms elicited from one additional consultant exhibited some variation: on one session, the pattern in (11) was produced whereas on a later session, the numeral distributive triggered g-zero alternations with all the stems in (11).

(11) Numeral distributive with stems ending in a bimoraic nucleus
/zurga:-A:dA:r/
[zursa:da:r] 'in bundles of six'
/dolo: ${ }^{\mathrm{n}}-\mathrm{A}: \mathrm{dA}: \mathrm{r} /$
[dolo:do:r] 'in bundles of seven'
/zu: ${ }^{\mathrm{n}}-\mathrm{A}: \mathrm{dA}: \mathrm{r} /$
[zu:ва:da:r] 'in bundles of a hundred'

Overall, the numeral distributive consistently shows up with a dorsal only when attached to the numeral / $z u:$ " ' hundred'. The other numeral stems ending in a bimoraic nucleus exhibit some variation, most commonly showing vowel deletion with the distributive. The resistance of this suffix to dorsal epenthesis is unexpected on the phonological insertion account. 


\section{Experimental evidence: The new augmentative}

The experimental part of this study addresses the question of how dorsal-zero alternations are applied with completely new, previously unseen morphemes. This study focuses on a "wug" test (Berko 1958) with novel affixes (Tessier 2012). Another way to address similar questions would be to conduct a recovery experiment (Chuang, Chang and Hsieh 2011) - present the native speakers with a form containing a dorsal and a novel affix, and test if they "recover" the suffix without a dorsal with other stem types. The recovery experiments are left for future research, but I thank an anonymous reviewer for suggesting these to me.

Since morphological accounts postulate that the alternating dorsal is part of an affix, the "wug" test was conducted with a novel affix rather than with novel stems. Indeed, both a phonological rule of /g/-insertion and a morphophonological account where relevant native affixes start with floating $/ \mathrm{g} /$ predict that novel stems will show a surface dorsal when attaching native affixes. The participants were taught a new affix, /A:bA/, with an augmentative meaning. Native augmentatives are absent in Buriat. This section details the experimental methods (5.1) and results (5.2), and ends with a summarising discussion (5.3).

\subsection{Method}

\subsubsection{Stimuli}

Prior to the experiment, about 50 nominal stems ending in either a consonant or a bimoraic nucleus were identified using the Buriat-Russian dictionary (Čeremisov 1973). These stems were paired with appropriate pictures (obtained via Google's image search function) and presented to the participants, in a picture-naming task, as slides on the screen of a 15-inch notebook computer. ${ }^{6}$ The participants were instructed to name the object they saw in Buriat using the phrase [эnэ ___ 'This is __ '. The main experiment used the same pictures as those in the picture-naming task. The stimulus set for each participant was designed to include only the words that $\mathrm{s} /$ he volunteered as a first reaction to the relevant picture. Although an effort was made to keep the stimulus set constant across participants, there were some inevitable differences. First, some of the participants occasionally failed to provide the intended Buriat word (usually replacing it with a Russian analog, or providing only a more general term such as "bird" for a picture of an eagle). Second, some of the relevant words were found to have both a dialectal and a literary variant, e.g. "saw" $/ \mathrm{x}^{\mathrm{j}} \mathrm{ur \theta}$ :/ [ $\mathrm{x}^{\mathrm{j}} \mathrm{ur \theta}$ :] (literary); /xurei/ [xure:] (dialectal). In these cases, the form that the given consultant volunteered first was used in the experiment provided that it was of the relevant phonological shape.

All stems used in the main experiment were between one and three syllables long. All stimuli were embedded in a carrier sentence [эnэ __ _ 'This is __.'. The stimuli for the training phase were presented both auditorily and orthographically. The training set consisted of eight consonant-final stimuli for most participants. Due to occasional failure to produce the relevant words in the picture-naming task, one participant (S09) received seven training items, one received six (S11), and another five (S10). The number of training items did not seem to affect the performance in the experiment.

\footnotetext{
${ }^{6}$ Due to power outages, an iPad 2 was used for picture naming with two participants. All participants did the main experiment with the same notebook computer.
} 
All of the training stimuli were recorded from the same consultant, who did not participate in the main experiment, under the recording conditions described in section 5.1.2. The unmodified training stimuli were recorded in a picture-naming task, and the modified stimuli bearing the novel affix were recorded from their orthographic representation. The vowels of the novel affix in modified stimuli varied according to the rules of vowel harmony (Poppe 1960). Each stimulus was recorded in the carrier phrase and repeated three times. The resulting sound files were segmented using Praat (Boersma and Weenink 2012), and the most suitable instance was embedded in the PowerPoint presentation for the experiment. All training stimuli were embedded with PowerPoint's maximal loudness setting. The training stimuli always included stems of different frontness harmony classes, which means that the novel affix was always changing its shape according to the rules of vowel harmony.

In addition to the training stimuli, there were 12 test stems for each participant: five stems ending in a long vowel or a diphthong, and seven stems ending in a consonant. In total, 108 test responses were obtained (12 responses from nine participants), of which 45 responses were potential cases of hiatus. The relatively small number of items per participant was motivated by the fact that pilot subjects exhibited visible signs of tiredness and started to increasingly modify the shape of the novel affix when additional items were added. The vowel-final test stimuli always included items of different harmony classes as well as items ending in both long vowels and diphthongs.

The consonant-final stimuli in the experiment never ended in $/ \mathrm{g} /$ since including these stems could independently explain possible /g/-insertion answers. Buriat nominal stems very often end in liquids $/ \mathrm{r} 1 /$, and this tendency was inevitably present in the data. However, the training stimuli always included items ending in non-liquids, such as /burgod/ 'eagle', /39mэs/ 'berry', and /nom/ 'book'. Whenever possible, consonant-final stems with a non-liquid ending were also included in the test set.

\subsubsection{Procedure}

At the time of the picture-naming task, all participants were unaware of the goal of the task. In the main experiment, the participants were instructed to remember the way in which the words are changed, and to guess the meaning associated with the change from pictures they were presented with. The participants were also encouraged to give feedback on whether they thought the experiment was game-like enough to be appropriate for children, since an extension for children was planned for future research.

At the training phase, the participants were presented with eight pairs of pictures, where the first picture (normal object) corresponded to a training item in unmodified form while the second picture (big object) corresponded to a training item with the novel affix. The training items were presented both orthographically (on a computer screen) and auditorily (through Sennheiser HD 202 headphones), and the participants were asked to repeat what they heard three times for each slide.

After the training phase, the participants took a short break and were asked what they thought the meaning of the new item was. The test stimuli were presented to the participants only orthographically. At the test phase, the participants were presented with pairs of pictures where the first picture (normal object) was paired with the corresponding unmodified stem while the 
second picture (big object) appeared with the gapped phrase [эnэ ___ 'This is __. The participants were instructed to fill the gap and to repeat the resulting phrase three times.

The test phase always started with five consonant-final items in order to give the participants some practice in attaching the new affix. The remaining two consonant-final test items were randomly interspersed with vowel-final test items in the final part of the test phase.

The experiment lasted between 10 and 20 minutes, and was performed in a quiet room. The participants' responses were recorded using an AKG C-1000S microphone (cardioid) and a Zoom H4N portable solid-state recorder. The participants were asked to repeat each response three times. In cases of occasional stutterings, self-corrections, or interruptions, further repetitions were prompted.

The results were segmented using Praat (Boersma and Weenink 2012). Each of the test responses was coded for whether it reflected frontness harmony. The responses to vowel-final test items were additionally coded for the hiatus resolution strategy they employed. Additional modifications to the novel affix were also noted, although these rarely occurred.

\subsubsection{Participants}

Nine speakers of Barguzin Buriat from the village of Baragkhan took part in the experiment. One of the speakers (S03) spent their childhood in Southern Buriatia (close to the Mongolian border) but had been living in the area for more than 40 years. Data from two additional speakers were discarded since these participants did not use the intended affix, and instead used a completely new morpheme or the Russian augmentative.

For sociolinguistic reasons, eight out of nine participants were female, aged between 37 and 65 . The one remaining participant (S09) was a man aged 17. The consultant's job was not considered socially appropriate for older men.

\subsection{Results}

Each of the test responses was consistent across the three repetitions. In rare cases of selfcorrection, the participants clearly insisted on just one response. The participants understood the instructions and used the novel affix (except for two additional subjects). Since the number of items and participants is relatively small, most of the results reported here are qualitative rather than quantitative. Nevertheless, the pattern is clear in many cases, as we shall see.

\subsubsection{Frontness harmony}

The participants correctly applied frontness harmony to the novel suffix in all cases. This was judged by the acoustics of the long vowel in the suffix /A:bA/. Short vowels in non-first syllables are subject to qualitative reduction, and the harmony class of the reduced vowel is much harder to judge acoustically. For that reason, all instances where the first long vowel of the suffix was deleted or shortened were excluded from assessing harmony patterns (see 5.2.3 on shortening). Across all participants, the long vowel of the novel suffix correctly appeared as [э:/ө:] after front-vowel stems in 32 responses. Each participant provided at least three such 
responses, each repeated three times. The long vowel of the suffix correctly appeared as [a:/o:] after back-vowel stems in 54 responses.

\subsubsection{Hiatus resolution}

The potential hiatus between a stem-final bimoraic nucleus and a long vowel of the novel suffix was always resolved. The strategies employed for hiatus resolution are summarised in (12) for each speaker.

(12) Buriat hiatus resolution with the novel affix
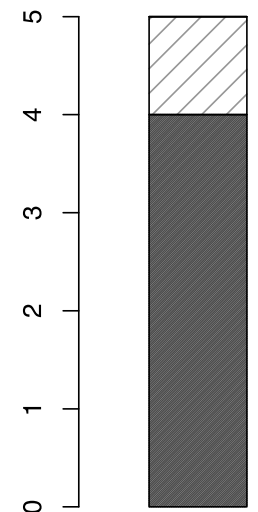

S09

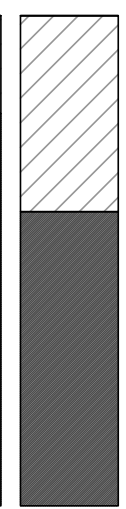

S03

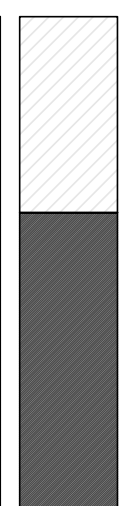

S02

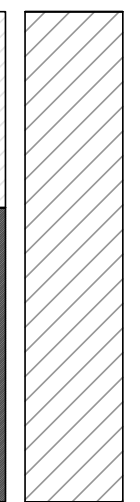

S05

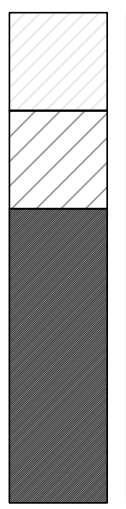

S04

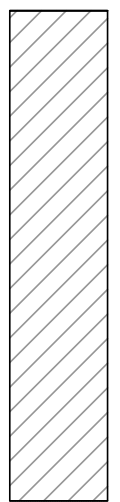

$\mathrm{S} 10$

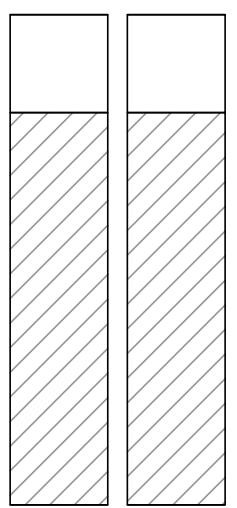

S07 S01

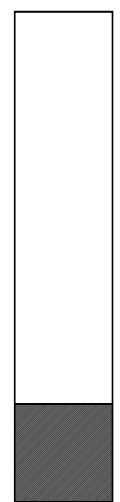

$\mathrm{S} 11$

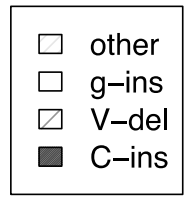

It can be observed that hiatus was resolved fairly consistently within each speaker. Six out of nine speakers gave either four or five responses using the same hiatus resolution strategy. $/ \mathrm{g} /-$ insertion was used as a consistent hiatus strategy by only one speaker (S11, four out of five responses). The remaining speakers together produced only two /g/-insertion responses (one each for S07 and S01), and the overall number of /g/-responses for these remaining speakers was not significantly different from zero (Fisher's exact test, $\mathrm{p}=0.25$ ). The $/ \mathrm{g} /$-responses for both S07 and S01 were produced with the same stem /bu:/ 'gun, rifle', yielding the novel augmentative [bu:ва:ba].

Four speakers consistently employed vowel deletion in hiatus (S01, S05, S07, S10). Vowel deletion was also commonly observed as an alternative response strategy for participants who overwhelmingly inserted a consonant other than /g/ (S02, S03, S04, S09). This latter group of participants is in fact rather heterogeneous. For one thing, the participant responses were less consistent within this group (three out of four group members gave only three of the same response). Furthermore, the inserted consonant was different for different participants. Two participants employed insertion of $/ \mathrm{r} /$, one participant inserted / $1 /$, and one participant inserted /b/. The insertion of liquids is consistent with the fact that many training and filler consonantfinal stems ended in $/ \mathrm{r} 1 /$ in the experiment (see section 5.3 for further discussion). The three responses coded as "other" in (12) constituted inserting an additional CV or CVC sequence between the stem and the suffix. 


\subsubsection{Shortening and other modifications}

In addition to hiatus repairs and harmony after vowel-final stems, the participants occasionally also applied other modifications to the novel affix. Shortening is perhaps most notable. The first vowel of the novel augmentative /A:bA/ was shortened in / $\mathrm{r}$-insertion repairs for participants S09 and S04 (7 responses total). The suffix was realised as $/ \mathrm{rAbA} /$ in these cases. Shortening did not occur in any other responses. The duration of the shortened vowel was quite substantial and hardly interpretable as an instantiation of $/ \mathrm{r} /$ release: mean 74,66 ms, sd 21,7 ms for consultant S09 (24 tokens); mean 61,37 ms, sd 13,4 ms for consultant S04 (18 tokens).

Across all participants, there were only seven responses where the suffix /A:bA/ was unexpectedly modified after consonant stems. These responses consisted of inserting a consonant or a vowel before the suffix (consultants S04 and S11) or truncating the suffix to $/ \mathrm{bA} /$ (one response from consultant S09).

\subsection{Discussion}

The consultants understood the task, most of them correctly identified the meaning of the novel suffix in the feedback, and the participants used the novel augmentative (with the exception of two speakers whose data were excluded). Importantly, the participants were not simply using the same string of segments all the time: they correctly varied the form of the affix according to the frontness harmony class of the stem. The extension of frontness harmony to the novel suffix also suggests (contra Samuels and Vaux 2019) that the participants did not ignore the rules of Buriat phonology when giving their responses.

The hiatus resolution strategies applied by the participants are not fully consistent with phonological /g/-insertion. Thus only one participant (S11) applied dorsal epenthesis while the majority of subjects either deleted one of the vowels or inserted some consonant other than $/ \mathrm{g} /$. The generalisation of native hiatus resolution strategies stands in sharp contrast with the native frontness harmony patterns which were applied consistently by all participants in all cases.

On the other hand, the results are consistent with morphological accounts of the Buriat dorsalzero alternation. The morphological account can only be distinguished from a phonological rulebased analysis if we adopt two assumptions. First, I assume that the existence of native affixes starting with a floating /g/ does not by itself force the learner to postulate a floating /g/ when novel suffixes are encountered. Second, I propose that the postulation of a latent segment or of floating features on a novel affix only occurs if the learner receives positive evidence of an alternation.

Given these assumptions, and based on a theoretically possible bias against dorsal insertion (see section 1), we may hypothesise that speakers will show a propensity to generalise not only /g/-zero alternations, but also other hiatus resolution strategies such as vowel deletion. Furthermore, the morphological account allows for possible suffixes which would start in non-dorsal floating consonants. The speakers may thus attempt to guess the floating features present on the given affix.

The results from two new environments are largely consistent with these two strategies being used. The numeral distributive may not have been encountered in sufficiently distinct environments to postulate a floating $/ \mathrm{g} /$, and therefore it often shows vowel deletion with 
stems with which it is rarely combined. Similarly, the participants in the "wug" test did not receive positive evidence of a /g/-zero alternation on the novel affix. The majority of the participants (to the extent that the responses were consistent within a subject) either applied vowel deletion or inserted a consonant other than $/ \mathrm{g} /$, consistent with attempting to guess the floater which is part of the suffix.

To summarise, the new data in sections 4 and 5 are consistent with the morphological accounts, but not with a phonological dorsal insertion rule. However, these results should be interpreted with a number of caveats in mind. There remains a possibility that the experiment did not yield robust generalisation of dorsal insertion due to high response variability and a lack of power. This study has a small number of participants and items, coupled with a high degree of variation in hiatus resolution strategies, and with some unexpected changes to the novel affix after consonant-final stems. For these reasons, the experiment does not allow us to make a statistically valid conclusion about the population of speakers as a whole. It remains to be seen how rarely the performance of /g/-inserting subject occurs in general in the studied dialect. Although the results are suggestive and come from two independent domains, it may be premature to conclude that $/ \mathrm{g} /$-insertion is not productive from these data alone.

\section{Analysis: The floating dorsal}

Although the hypothesised dorsal insertion rule arguably provides an elegant account of the native data in (3-5), two kinds of novel environments provide preliminary evidence against the productivity of dorsal insertion. First, a rarely occurring numeral distributive suffix was frequently found to trigger vowel deletion rather than dorsal insertion with the stems with which it is rarely combined (section 4). This suffix induced dorsal insertion only in one speaker, and only variably. Second, the experiment with a novel suffix yielded no conclusive support for extension of dorsal insertion to new environments since only one speaker consistently applied this strategy. While more extensive experimental data may be needed to fully establish that dorsal insertion is non-productive, it makes sense at this point to briefly consider a possible alternative analysis of the complete Buriat dataset. This section spells out such an alternative account assuming a floating $/ \mathrm{g} /$, and comments on the predictions of this theory.

The proposed account captures the general alternation pattern while abstracting away from a couple of affixes which are clearly suppletive (see section 3.4). The approach presented here is cast within Optimality Theory (OT; Prince and Smolensky 2004) and it implements the floating /g/ idea in line with existing work in autosegmental OT (Zoll 1996; Akinlabi 1996, 2011; Trommer 2011; Bermúdez-Otero 2012 amongst others).

I will assume that all affixes that trigger dorsal-zero alternations come with the floating features [dorsal] and [+voice] at the beginning, which is written as $/ \mathrm{g} /$ in underlying forms. The voicing specification is necessary to ensure that the floating features are realised as a voiced segment $[\mathrm{g} / \mathrm{\gamma} / \mathrm{G} / \mathrm{H}]$ rather than as voiceless. The quality of a segment alternating with zero is thus encoded as part of the representation of the particular morphemes.

The exact realisation of Buriat /g/ depends on the quality of the vowels in the word: dorsal in front-vowel words and uvular in back-vowel words, with a possibility of intervocalic lenition. These alternations equally apply to all dorsals regardless of their derivational history. In what follows, I will abstract away from these alternations. Although they could be analysed by some 
ad hoc constraint requiring $\mathrm{VC}$ feature sharing, analogous to the spreading rule proposed for Mongolian by Svantesson et al. (2005), these alternations are somewhat unique in the typology of harmony processes since they present a case of an arguably non-local vowel-consonant place feature interaction (Padgett 2011, Rose and Walker 2011, Becker 2016). Providing a theoretically-informed analysis of these alternations would lead us too far afield.

In Buriat, the floating dorsal can only be realised by inserting a root node, in violation of the constraint DEP defined in (13) (McCarthy and Prince 1995, 1999). Alternatively, the realisation of the floating dorsal could be analysed as splitting, i.e. the creation of a root node corresponding to an underlying vowel (Staroverov 2014). The difference between the two approaches to epenthesis is irrelevant here.

(13) DEP: assign a violation mark for every surface segmental root node which does not have a correspondent in the input

This analysis treats the Buriat dorsal-zero alternation as an epenthesis process where an empty root node rather than a dorsal consonant is inserted.

Segmental insertion is generally disallowed in Buriat, and therefore the floating /g/ normally remains unassociated, hence violating the constraint *FLOAT (Wolf 2007).

(14) *FLOAT: assign a violation mark for every feature that is not associated to a segmental root node

This is illustrated in the tableau in (15) showing attachment of the instrumental suffix $/{ }^{\mathrm{g}} \mathrm{A}: \mathrm{r} /$ to a consonant-final stem / $\mathrm{ht}: 1 /$ 'tail' (3b). This paper combines the comparative tableau format of Prince (2002) with numbers showing violation marks.

Floating dorsal is normally left unrealised

\begin{tabular}{|c|c|c|c|}
\hline & /hu:1-gA:r/ & DEP & *FLOAT \\
\hline $\mathrm{a}$. & fht:l(g)):r & & 2 \\
\hline b. & hu:lgэ:r & W1 & $\mathrm{L}$ \\
\hline
\end{tabular}

The losing candidate $(15 \mathrm{~b})$ represents an attempt to realise the floater which fatally violates DEP. The winning candidate (15a) has a floating dorsal, shown in parentheses. These floating features remain unassociated, and hence not phonetically realised.

No constraint specifically protects the floating material (cf. MAX-FLOAT in Wolf (2007)) and therefore a candidate [fu:ls:r], which would remove the floating features, would tie with the winner in (15a). ${ }^{7}$ My constraints do not distinguish between the two representations, and this is arguably a welcome result since they are pronounced the same. When the floating dorsal is realised, its appearance is required not by a constraint requiring preservation of floaters but by the constraint DEP-PLACE in (16) (Rubach 2000, Uffmann 2007) which prohibits inserting new features. This will be illustrated in more detail in the tableau in (21).

(16) DEP-PLACE: assign a violation mark for each place node without an input correspondent

\footnotetext{
${ }^{7}$ I am grateful to an anonymous reviewer for questions on this issue.
} 
Another case of floating dorsal non-realisation comes from hiatus environments with a short vowel, e.g. /nabfa- ${ }^{\mathrm{g}} \mathrm{A}: \mathrm{r} / \rightarrow$ [nabfa:r] 'leaves-INSTR' (4). In these cases, inserting a root node could help to avoid a violation of ONSET (Prince and Smolensky 2004). Nevertheless, vowel deletion is preferred in this environment because MAX is ranked below DEP. The relevant constraints are defined in (17) and (18).

(17) ONSET: assign a violation mark for every surface syllable without an onset consonant

(18) MAX: assign a violation mark for every underlying segmental root node which does not have a correspondent in the output

The analysis of Buriat short vowel deletion in hiatus is presented in (19). Here and below, dots show syllabification. Again, a candidate removing the floating features [nabfa:r] would do just as well as the winner.

Hiatus resolution via vowel deletion with short vowels

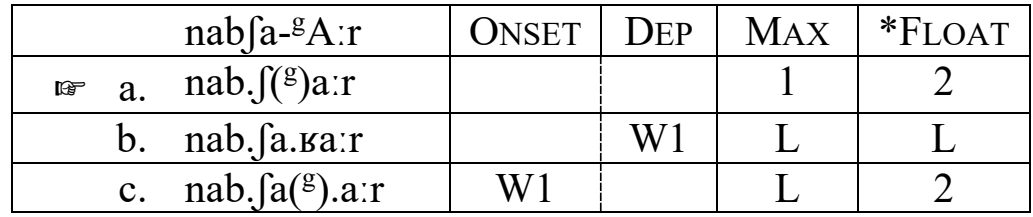

Buriat does not tolerate word-medial onsetless syllables, and therefore when two vowels come together at a morpheme boundary, hiatus has to be resolved, with the result that (19c) cannot win. However, it is better to delete a stem-final short vowel and leave the $/ \mathrm{g} /$ floating (or delete it) than to insert a root node (DEP $>>$ MAX). Therefore, the deletion candidate (19a) beats the insertion candidate (19b).

When two bimoraic nuclei come together in Buriat, deletion is not applicable. The special behaviour of long vowels in hiatus environments is well-documented cross-linguistically (Casali 1998, Staroverov 2014). In Buriat, the set of long vowels is further extended to include all bimoraic nuclei, i.e. long vowels and diphthongs. Diphthongs also pattern together with long vowels with respect to rounding harmony (Poppe 1960). Here, I follow Casali (1998) and Beckman (1998) in assuming that bimoraic nuclei are protected by a special family of positional faithfulness constraints. In particular, MAX-BIMORAIC (20) protects bimoraic vowels from deletion.

(20) MAX-BIMORAIC: assign a violation mark for every underlying bimoraic segment which does not have a correspondent in the output

The highly ranked MAX-BIMORAIC protects long vowels from deletion in hiatus environments. In this case, DEP is violated instead: a consonant root node is inserted, providing a docking site for the floating $/ \mathrm{g} /$. This is illustrated in (21) with the analysis of the mapping $/ \mathrm{bu}:-{ }^{\mathrm{g}} \mathrm{A}: \mathrm{r} / \rightarrow$ [bu:ва:r] 'rifle-INSTR' (5b). 
(21) Hiatus resolution via root node insertion between two long vowels

\begin{tabular}{|c|c|c|c|c|c||c|}
\hline$\left[\right.$ bu:- $\left.{ }^{\mathrm{g}} \mathrm{A}: \mathrm{r}\right]$ & ONSET & MAX-BIMOR & DEP & MAX & *FLOAT & DEP-PLC \\
\hline a. bu:.5a:r & & & 1 & & & \\
\hline b. bu:( $\left.{ }^{\mathrm{g}}\right) \mathrm{r}$ & & $\mathrm{W} 1$ & $\mathrm{~L}$ & $\mathrm{~W} 1$ & $\mathrm{~W} 2$ & \\
\hline c. bu:( $\left.{ }^{\mathrm{g}}\right) \cdot \mathrm{a}: \mathrm{r}$ & $\mathrm{W} 1$ & & $\mathrm{~L}$ & & $\mathrm{~W} 2$ & \\
\hline d. bu:.ha:r & & & 1 & & & W1 \\
\hline
\end{tabular}

The winning candidate (21a) keeps both input long vowels and avoids the potential ONSET violation through floating /g/ realisation. The competitors, on the other hand, either delete a bimoraic nucleus (21b) or have a violation of ONSET (21c).

The candidate (21d) is harmonically bounded by the winner, but it illustrates an important point about my analysis. I assume that insertion of place features is penalised by the constraint DEPPLACE; similar constraints are often used in the analysis of glide insertion (Kawahara 2002, Rubach 2000, Uffmann 2007, Naderi and van Oostendorp 2011). The sheer existence of this constraint guarantees that epenthesis will be kept to a minimum: if the epenthetic root node can get its place from the underlying floating features, it will always do so. The candidate [bu:.ha:r] can never win in the present system, although the addition of constraints against feature association (*SPREAD, Kirchner (1993)) could "unbind" such candidates. ${ }^{8}$

Of course, a bare root node together with dorsal place and [+voice] does not yield a full specification of Buriat $/ \mathrm{g} /$. Most of the other features are left unspecified and filled in by Buriat phonological and phonetic processes.

The proposed grammar of Buriat hiatus correctly predicts that the floating /g/ should be highly restricted in its distribution: it should only be found in a suffix-initial position before a bimoraic nucleus. According to Richness of the Base, we have to consider inputs where floating /g/ would occur in other environments, but none of these inputs would give surface evidence of a dorsalzero alternation. Indeed, if $/ \mathrm{g} /$ occurred next to a short vowel or consonant, it would not have a chance to be realised since its realisation is always triggered by MAX-BIMORAIC. On the other hand, if /g/ occurred morpheme-internally between two bimoraic nuclei, it would always be realised and thus equivalent to a fully specified $/ \mathrm{g} /$. In both of these cases, the learner would fail to postulate a floating segment because input optimisation would crucially rely on the constraint prohibiting floating material, namely *FLOAT. The only environment where a floating /g/ can be reasonably postulated is at the edge of a morpheme next to a bimoraic nucleus. Since Buriat has no prefixes and very limited compounding and reduplication, this is equivalent to the environment where /g/ actually occurs.

As argued in section 5.3, this account is compatible with the new experimental and elicitation data in sections 4-5 on the assumption that postulating a floating $/ \mathrm{g} /$ requires positive evidence. On the floating $/ \mathrm{g} /$ account, nothing in principle excludes suffixes with other floating features, and some of the experimental responses with consonant insertion may be interpreted as an indication that Buriat grammar allows other floaters.

\footnotetext{
${ }^{8}$ If [ $[\mathrm{h}]$ was placeless, [h]-insertion would satisfy DEP-PLACE. However, there is no evidence that $[\mathrm{h}]$ is placeless in Buriat. A candidate inserting [ $\mathrm{h}$ ] is also harmonically bound by the winner due to DEP-LAR, a constraint against insertion of laryngeal features.
} 
Interestingly, while bimoraic vowel deletion does not occur with the native data, it is attested with the numeral distributive and in the experiment. These examples could be used as evidence for further refining our grammatical model of Buriat. The responses with long vowel deletion evidently do violate MAX-BIMORAIC, which we were assuming to be top ranked so far. However, in the absence of a floating /g/, consonant epenthesis would always involve insertion of place features. We can therefore assume that Buriat prohibits place insertion via a ranking DEP-PLACE $>$ MAX-BIMORAIC, relevant at least for the speakers who produced long-vowel deletion in the absence of a floater.

To summarise, this section has provided an autosegmental OT account of the Buriat dorsal-zero alternation. This account does not postulate a general dorsal insertion process, it is compatible with the evidence in sections 4-5, and it correctly derives the distribution of the floating $/ \mathrm{g} /$.

\section{Conclusion}

This paper has provided a detailed examination of the Buriat dorsal-zero alternation based on new elicitation and experimental data from the Barguzin dialect. While Morley (2015) argues that deletion and insertion analyses generally cannot be separated from each other, the new elicitation data in this paper present counterexamples to the deletion analysis (section 3.2). Thus, the deletion hypothesis seems falsifiable, at least in Buriat.

The remaining two kinds of accounts include morphological pre-specification and general phonological epenthesis. The phonological analysis postulates a general dorsal epenthesis process. However, this process does not appear to be generalised to novel environments in at least two kinds of situations. First, the relatively infrequent numeral distributive /-A:dA:r/ does not trigger dorsal epenthesis with stems with which it was probably never seen before by the consultants. Second, when nine Buriat speakers were taught a novel augmentative suffix /-A:bA/, only one speaker systematically generalised dorsal insertion to this suffix. This is in contrast with frontness harmony which was always consistently applied by all speakers. Although the experimental results are suggestive, the relatively small number of items and participants coupled with the high degree of response variability makes it difficult to interpret the data quantitatively.

A theoretical model of the Buriat dorsal-zero alternation was proposed in section 6 . This model encodes the quality of the alternating segment as an underlying property of the relevant suffixes. The model is compatible with the new data in this paper, on the assumption that postulating a floater requires positive evidence.

To summarise, the present results suggest that the hypothesised dorsal insertion rule is not fully productive in Buriat. The data are thus better captured by the floating $/ \mathrm{g} /$ account. To address the shortcomings of the present experiment, the predictions of the morphological analysis should ideally be tested in future studies with greater power.

Buriat epenthesis is known as a potential counterexample to the view that dorsal consonants are relatively marked (Lombardi 2002, de Lacy 2006, de Lacy and Kingston 2013). If the results of this article are on the right track, then this counterexample may be due to a non-productive pattern. Of course, the investigation of Buriat has only indirect implications for markedness, since a detailed investigation of the reportedly unmarked glottals and coronals is impossible in this language. The present results are also consistent with a naturalness bias for learning and 
generalising phonological alternations (Wilson 2006, Zuraw 2007, Zhang and Lai 2010, BaerHenney and van de Vijver 2012, White 2014): despite the relatively robust evidence, the arguably unnatural dorsal epenthesis pattern is productive only for one consultant. The link between the Buriat results and naturalness is also indirect, since the phonetically natural patterns are not considered here.

\section{Acknowledgements}

This study is dedicated to Akin Akinlabi whose insightful and challenging comments always inspired me to obtain primary data through fieldwork and to look deeper into phonological patterns.

I thank my Buriat consultants for their eager engagement, patience, and hospitality. Thanks to William Bennett and Seunghun Lee, and to two anonymous reviewers for their comments. Many thanks to Sergei Tatevosov both for his astute comments on Buriat, and for organising the Buriat field trips. I am grateful to Sven Grawunder for sharing his fieldwork experience with me. For comments and questions at various stages of this project, I am indebted to Asya Achimova, Michael Becker, Andrew Nevins, Sara Finley, Paul de Lacy, Rebecca Morley, Jochen Trommer, Colin Wilson, and Kie Zuraw. Many thanks to all my fellow fieldworkers, especially Pavel Koval, Ilya Kuryanov, Dmitry Privoznov, Galina Sim, Maria Vassilyeva, and Dmitry Zelensky. All errors are my own. This study was supported by Leipzig University, Wayne State University, and the German Research Foundation (DFG Research Training Group GRK 2011).

\section{References}

Akinlabi, A. 1996. Featural affixation. Journal of Linguistics 32(2): 239-289. https://doi.org/ $\underline{10.1017 / \mathrm{s} 0022226700015899}$

Akinlabi, A. 2011. Featural affixes. In M. Van Oostendorp, C.J. Ewen, E. Hume and K. Rice (eds.) The Blackwell companion to phonology, vol. 3. Malden: Blackwell. pp. 1945-1971. https://doi.org/10.1002/9781444335262.wbctp0082

Alderete, J. and A. Kochetov. 2009. Japanese mimetic palatalization revisited: Implications for conflicting directionality. Phonology 26(3): 369-388. https://doi.org/10.1017/s095267570999 $\underline{0212}$

Baer-Henney, D. and R. van de Vijver. 2012. On the role of substance, locality, and amount of exposure in the acquisition of morphophonemic alternations. Laboratory Phonology 3(2): 221-249. https://doi.org/10.1515/lp-2012-0013

Baković, E. 1999. Deletion, insertion and symmetrical identity. Available online: http://roa. rutgers.edu/files/300-0299/roa-300-bakovic-2.pdf (Accessed 11 October 2019).

Becker, L. 2016. Vowel-Consonant Harmony in Uyghur. Unpublished manuscript, Leipzig University.

Beckman, J. 1998. Positional Faithfulness. Unpublished $\mathrm{PhD}$ dissertation, University of Massachusetts, Amherst. 
Berko, J. 1958. The child's learning of English morphology. Word 14(2-3): 150-177. https://doi.org/10.1080/00437956.1958.11659661

Bermúdez-Otero, R. 2012. The architecture of grammar and the division of labour in exponence. In J. Trommer (ed.) The phonology and morphology of exponence. Oxford: Oxford University Press. pp. 8-83.

Blevins, J. 2008. Consonant epenthesis: Natural and unnatural histories. In J. Good (ed.) Linguistic universals and language change. Oxford: Oxford University Press. pp. 79-107. https://doi.org/10.1093/acprof:oso/9780199298495.003.0004

Boersma, P. and D. Weenink. 2012. Praat: Doing phonetics by computer. (Software). www.praat.org.

Bondarenko, T. 2017a. Passivization of matrix predicates in the light of constructions with accusative subjects: The case of Barguzin Buryat. Ural-Altaic Studies 26(3): 117-126.

Bondarenko, T. 2017b. ECM in Buryat and the optionality of movement. WAFL 12 Proceedings. Cambridge, MA: The MIT Press.

Bondarenko, T. 2018a. Voice restructuring in Buryat. WAFL 13 Proceedings. Cambridge, MA: The MIT Press.

Bondarenko, T. 2018b. žə-converbs in Barguzin Buryat as reduced sentential arguments. Voprosy Iazykoznaniya 2018(3): 40-71.

Buraev, I.D. 1959. Zvukovoi sostav buriatskogo iazyka. Ulan-Ude: Buriatskii kompleksnyi nauchno-issledovatel'skii institut SO AN SSSR.

Casali, R. 1998. Resolving hiatus. New York: Taylor and Francis.

Čeremisov, K.M. 1973. Buriatsko-Russkii Slovar'. Moskva: Sovetskaya Entsiklopediya.

Chuang, C., Y. Chang and F. Hsieh. 2011. Productivity in Taiwanese tone sandhi redux. Proceedings ICPhS 17: 492-495.

Churma, D.G. 1977. On choosing between linguistic analyses: A reply to Klausenburger. Lingua 42(2): 131-152. https://doi.org/10.1016/0024-3841(77)90023-7

De Lacy, P. 2002. The Formal Expression of Markedness. Unpublished PhD dissertation, University of Massachusetts, Amherst.

De Lacy, P. 2003. Maximal words and the Maori passive. In J.J. McCarthy (ed.) Optimality Theory in phonology: A reader. Oxford: Blackwell. pp. 495-512. https://doi.org/10.1002/ $\underline{9780470756171 . \operatorname{ch} 27}$

De Lacy, P. 2006. Markedness: Reduction and preservation in phonology. Cambridge: Cambridge University Press. 
De Lacy, P. and J. Kingston. 2013. Synchronic explanation. NLLT 31(2): 287-355.

Delattre, P.C., A.M. Liberman and F.S. Cooper. 1955. Acoustic loci and transitional cues for consonants. The Journal of the Acoustical Society of America 27(4): 769-773. https://doi.org/ $\underline{10.1121 / 1.1908024}$

Gick, B. 1999. A gesture-based account of intrusive consonants in English. Phonology 16(1): 29-54. https://doi.org/10.1017/s0952675799003693

Hale, K. 1973. Deep-surface canonical disparities in relation to an analysis and change: An Australian example. In T. Sebeok (ed.) Current trends in linguistics. The Hague: Mouton. pp. 401-458. https://doi.org/10.1515/9783111418797-018

Hall, T.A. 2013. How common is r-Epenthesis? Folia Linguistica 47(1): 55-88.

Harris, J. 1994. English sound structure. Oxford: Blackwell.

Hayes, B., P. Siptár, K. Zuraw and Z. Londe. 2009. Natural and unnatural constraints in Hungarian vowel harmony. Language 85(4): 822-863. https://doi.org/10.1353/lan.0.0169

Kawahara, S. 2002. Feature recycling: Hiatus resolution by way of glide formation in Japanese. Paper presented at Japan Phonology Association, International Christian University, Tokyo.

Kirchner, R. 1993. Turkish Vowel Harmony and Disharmony: An Optimality Theoretic Account. Unpublished manuscript, University of Alberta. Available online: http://roa.rutgers.

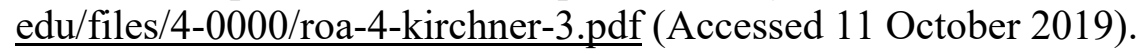

Klausenburger, J. 1974. Rule inversion, opacity, conspiracies: French liaison and elision. Lingua 34(2-3): 167-179. https://doi.org/10.1016/0024-3841(74)90015-1

Klausenburger, J. 1977. Deletion vs. epenthesis: Intra- vs. inter-paradigmatic arguments in linguistics. Lingua 42(2): 153-160. https://doi.org/10.1016/0024-3841(77)90024-9

Liberman, A.M., P.C. Delattre, L.J. Gertsman and F.S. Cooper. 1956. Tempo of frequency change as a cue for distinguishing classes of speech sounds. Journal of Experimental Psychology 52(2): 127-137. https://doi.org/10.1037/h0041240

Lombardi, L. 2002. Coronal epenthesis and markedness. Phonology 19(2): 219-251. https:// doi.org/10.1017/s0952675702004323

McCarthy, J.J. 1991. Synchronic rule inversion. In L.A. Sutton, C. Johnson and R. Shields (eds.) Proceedings of the Seventeenth Annual Meeting of the Berkeley Linguistics Society: General Session and Parasession on The Grammar of Event Structure. Berkeley: University of California. pp. 192-207. https://doi.org/10.3765/bls.v17i0.1628

McCarthy, J.J. 1993. A case of surface constraint violation. Canadian Journal of Linguistics 38(2): 169-195. 
McCarthy, J.J. and A. Prince. 1995. Faithfulness and Reduplicative Identity. Unpublished manuscript, University of Massachusetts and Rutgers University. https://doi.org/10.1017/S0008413100014730

McCarthy, J.J. and A. Prince. 1999. Faithfulness and identity in prosodic morphology. In R. Kager, H. van der Hulst and W. Zonneveld (eds.) The prosody-morphology interface. Cambridge, MA: Cambridge University Press. pp. 218-309. https://doi.org/10.1017/cbo97805 $\underline{11627729.008}$

Morley, R.L. 2015. Deletion or epenthesis? On the falsifiability of phonological universals. Lingua 154: 1-26. https://doi.org/10.1016/j.lingua.2014.11.002

Morley, R.L. 2018. Is phonological consonant epenthesis possible? A series of artificial grammar learning experiments. Phonology 35(4): 649-688. https://doi.org/10.1017/s095267 $\underline{5718000234}$

Naderi, N. and M. van Oostendorp. 2011. Reducing the number of Farsi epenthetic consonants. In A. Korn, G. Haig, S. Karimi and P. Samvelian (eds.) Topics in Iranian linguistics. Weisbaden: Ludwig Reichert Verlag. pp. 153-166.

O’Connor, J.D., L.J. Gertsman, A.M. Liberman, P.C. Delattre and F.S. Cooper. 1957. Acoustic cues for the perception of initial $/ \mathrm{w}, \mathrm{j}, \mathrm{r}, 1 /$ in English. Word 13(1): 24-43. https://doi.org/10.1080/00437956.1957.11659626

Padgett, J. 2011. Consonant-vowel place feature interactions. In M. van Oostendorp, C.J. Ewen, E. Hume and K. Rice (eds.) The Blackwell companion to phonology, vol. 3. Malden: Blackwell. pp. 1761-1786. https://doi.org/10.1002/9781444335262.wbctp0075

Poppe, N.N. 1938. Grammatika Buriat-Mongol'skogo iazyka. Moskva, Leningrad: Izdatel'stvo AN SSSR.

Poppe, N.N. 1960. Buriat grammar. Bloomington: Indiana University Publications.

Prince, A. 2002. Arguing Optimality. Available online: http://roa.rutgers.edu/files/5621102/562-1102-PRINCE-0-0.PDF (Accessed 16 October 2019).

Prince, A. and P. Smolensky. 2004. Optimality Theory. Constraint interaction in generative grammar. Malden: Blackwell. https://doi.org/10.1002/9780470756171.ch1

Radnaev, E.R. 1965. Barguzinskiy govor. In I.D. Buraev and C.B. Cydendambaev (eds.) Issledovanie burjatskih govorov 1 (Trudy Burjatskogo Kompleksnogo NaucnoIssledovatel'skogo Instituta). Ulan-Ude: SO AN SSSR. pp. 71-107.

Radnaeva, L.D. 2003a. The two types of transcription (the Buryat Language Database). Proceedings of the $15^{\text {th }}$ International Congress of Phonetic Sciences, 3-9 August 2003, Barcelona, Spain. pp. 2737-2740.

Radnaeva, L.D. 2003b. Zvukovaja Forma Sovremennogo Buriatskogo Jazyka. Teoreticheskije 
i Prakticheskije Aspekty Kachestvennogo i Kolichestvennogo Analiza. Unpublished $\mathrm{PhD}$ dissertation, Saint Petersburg State University.

Radnaeva, L.D. 2006. Phonetic research of the sound form of modern Buryat language. Proceedings of the XIth International Conference "Speech and Computer". Saint Petersburg. pp. 577-582.

Radnaeva, L.D. 2008. Issledovanie zvukovoi formy sovremennogo buriatskogo jazyka. Proceedings of the $36^{\text {th }}$ International Conference "Problemy Izucheniya, sokhraneniya $i$ prepodavaniya jazykov narodov Rossii." Saint Petersburg.

Rice, K. 2008. Review of de Lacy (2006). Phonology 25(2): 361-371.

Rose, S. and R. Walker. 2011. Harmony systems. In J. Goldsmith, J. Riggle and A.C.L. Yu (eds.) The handbook of phonological theory. Oxford: Blackwell. pp. 240-290. https://doi.org/ $\underline{10.1002 / 9781444343069 . \operatorname{ch} 8}$

Rubach, J. 2000. Glide and glottal stop insertion in Slavic languages: A DOT analysis. Linguistic Inquiry 31(2): 271-317. https://doi.org/10.1162/002438900554361

Samuels, B. and B. Vaux. 2019. Mongolic dorsals are truly epenthetic. Available online: http://radical.cnrs.fr/samuels-vaux-mongolic-dorsals-are-truly-epenthetic/ $\quad$ (Accessed 16 October 2019).

Sanžeev, G.D. 1941. Grammatika Buriat-Mongol'skogo iazyka. Moskva, Leningrad: Izdatel'stvo AN SSSR.

Sanžeev, G.D., T.A. Bertagaev and Ts. B. Tsidendambaev (eds.) 1962. Grammatika buriatskogo iazyka. Moskva: Izdatel'stvo Vostochtoi Literatury.

Skribnik, E. 2003. Buryat. In J. Janhunen (ed.) The Mongolic languages. London and New York: Routledge. pp. 102-128.

Staroverov, P. 2014. Splitting Theory and Consonant Epenthesis. Unpublished PhD dissertation, Rutgers University.

Staroverov, P. 2016. Productivity of the Buriat dorsal-zero alternation. In C. Hammerly and B. Prickett (eds.) Proceedings of NELS 46. Amherst, MA: GLSA Publications. pp. 207-220.

Svantesson, J.-O., A. Tsendina, A. Karlsson and V. Franzén. 2005. The phonology of Mongolian. Oxford and New York: Oxford University Press.

Tessier, A.-M. 2012. Testing for OO-faithfulness in the acquisition of consonant clusters. Language Acquisition: A Journal of Developmental Linguistics 19(2): 144-173. https://doi.org/ $\underline{10.1080 / 10489223.2012 .660552}$

Tranel, B. 1981. Concreteness in generative phonology: Evidence from French. Berkeley: University of California Press. 
Tranel, B. 1996. French liaison and elision revisited: A unified account within Optimality Theory. In C. Parodis, C. Quicoli, M. Saltarelli and M.L. Zubizarreta (eds.) Aspects of romance linguistics. Washington, DC: Georgetown University Press. pp. 433-455.

Trommer, J. 2011. Phonological Aspects of Western Nilotic Mutation Morphology. Unpublished habilitation thesis, University of Leipzig.

Uffmann, C. 2007. Intrusive [r] and optimal epenthetic consonants. Language Sciences 29(23): 451-476. https://doi.org/10.1016/j.langsci.2006.12.017

Uffmann, C. 2014. Possible Epenthetic Segments: The Role of Faithfulness. Handout from a talk presented at the $22^{\text {nd }}$ Manchester Phonology Meeting.

Vaux, B. and B. Samuels. 2017. Consonant epenthesis and markedness. In B. Samuels (ed.) Beyond markedness in formal phonology. Amsterdam: Benjamins. pp. 69-100. https://doi.org/ $\underline{10.1075 / 1 \mathrm{a} .241 .04 \mathrm{vau}}$

Walker, R. 1994. Buriat syllable weight and head prominence. Phonology at Santa Cruz vol. 3, Santa Cruz: Linguistics Research Center, University of California. pp. 99-110.

Wetzels, L.W. 2002. Les adjectifs pré-nominaux du français: Formes longues et formes féminines. In H. Jacobs and L. Wetzels (eds.) Liber amicorum Bernard Bichakjian. Maatsricht: Shaker Publications. pp. 273-306.

White, J. 2014. Evidence for a learning bias against saltatory phonological alternations. Cognition 130(1): 96-115. https://doi.org/10.1016/j.cognition.2013.09.008

Wilson, C. 2006. Learning phonology with substantive bias: An experimental and computational study of velar palatalization. Cognitive Science 30(5): 945-982. https://doi.org/10.1207/s15516709 $\operatorname{cog} 0000 \quad 89$

Wolf, M. 2007. For an autosegmental theory of mutation. In L. Bateman, M. O'Keefe, E. Reilly and A. Werle (eds.) UMOP 32: Papers in Optimality Theory III. Amherst, MA: GLSA. pp. 315-404.

Wright, R. 2004. A review of perceptual cues and cue robustness. In B. Hayes, R. Kirchner and D. Steriade (eds.) Phonetically based phonology. Cambridge: Cambridge University Press. pp. 34-57. https://doi.org/10.1017/cbo9780511486401.002

Zhang, J. 2016. Using nonce-probe tests and auditory priming to investigate speakers' phonological knowledge of tone sandhi. Online proceedings from the $5^{\text {th }}$ Tonal Aspects of Language Symposium, 24-27 May 2016. pp. 12-18. https://doi.org/10.21437/tal.2016-3

Zhang, J. and Y. Lai. 2008. Phonological knowledge beyond the lexicon in Taiwanese double reduplication. In Y.C.-E. Hsiao, H.-C. Hsu, L.H. Wee and D.-A. Ho (eds.) Interfaces in Chinese phonology: Festschrift in honor of Matthew Y. Chen on his 70th birthday. Taiwan: Academia Sinica. pp. 183-222. 
Zhang, J. and Y. Lai. 2010. Testing the role of phonetic knowledge in Mandarin tone sandhi. Phonology 27(1): 153-201. https://doi.org/10.1017/s0952675710000060

Zhang, J., Y. Lai and C. Sailor. 2011. Modeling Taiwanese speakers' knowledge of tone sandhi in reduplication. Lingua 121(2): 181-206. https://doi.org/10.1016/j.lingua.2010.06.010

Zoll, C. 1996. Parsing below the Segment in a Constraint Based Framework. Unpublished PhD dissertation, University of California, Berkeley.

Zuraw, K. 2007. The role of phonetic knowledge in phonological patterning: Corpus and survey evidence from Tagalog infixation. Language 83(2): 277-316. https://doi.org/10.1353/lan. $\underline{2007.0105}$ 